\title{
Protesting or Justifying? \\ A Latent Class Model for Contingent Valuation with Attitudinal Data
}

\author{
Maria A. Cunha-e-Sá, ${ }^{a *}$ Lívia Madureira, ${ }^{b}$ \\ Luis C. Nunes, ${ }^{a}$ Vladimir Otrachshenko ${ }^{a}$ \\ ${ }^{a}$ Universidade Nova de Lisboa, \\ Faculdade de Economia \\ ${ }^{b}$ Universidade de Trás-os-Montes e Alto Douro, \\ Departamento de Economia, Sociologia e Gestão
}

March 25, 2010

${ }^{*}$ Corresponding author: Maria A. Cunha-e-Sá; Address: Faculdade de Economia, Universidade Nova de Lisboa, Campus de Campolide, 1099-032 Lisboa, Portugal; Phone: (351)213801600; Email: mcunhasa@fe.unl.pt. 


\title{
Protesting or Justifying? A Latent Class Model for Contingent Valuation with Attitudinal Data
}

\author{
March 25, 2010
}

\begin{abstract}
This article develops a latent class model for estimating willingness-to-pay for public goods using simultaneously contingent valuation (CV) and attitudinal data capturing protest attitudes related to the lack of trust in public institutions providing those goods. A measure of the social cost associated with protest responses and the consequent loss in potential contributions for providing the public good is proposed. The presence of potential justification biases is further considered, that is, the possibility that for psychological reasons the response to the CV question affects the answers to the attitudinal questions. The results from our empirical application suggest that psychological factors should not be ignored in CV estimation for policy purposes, allowing for a correct identification of protest responses.
\end{abstract}

Keywords: Public goods, quality of institutions, protest responses, contingent valuation, justification bias, latent class model

JEL Classification Numbers: C35, C85, Q51 
Stated preference (SP) survey techniques, such as the Contingent Valuation (CV) approach, are widely used to elicit the economic value of public goods, as land preservation, biodiversity, and other environmental amenities. Often, public agencies rely on those estimates to decide about the adoption of alternative policies. However, as pointed out by Carson and Groves [6], and Johnston and Duke [12], the elicited willingness to pay (WTP) may be affected by the policy process through which the public good will be provided. In particular, in the literature, the lack of trust in institutions is identified as one of the factors that may contribute to the presence of protest responses, that is, when respondents do not state their true value of the good in question (see Mitchell and Carson [20]). As a result, the use of standard SP methods without accounting for protest responses will not be able to elicit the true economic value that would allow for optimally providing the public good at stake, with a resulting cost to society.

Often, the identification of protestors relies on the answers to a set of attitudinal questions posed to respondents that have stated a zero WTP or refused to pay the proposed bids, as in Jorgensen, Syme, Bishop and Nancarrow [14], Jakobsson and Dragun [11], among others. As an alternative, all respondents can be asked to answer the attitudinal questions. In fact, as shown by Jorgensen and Syme [13], Dziegielewska and Mendelsohn [7], and Meyerhoff and Liebe [18], [19], respondents that are willing to pay may also exhibit protest responses. One may use the responses to those attitudinal questions as indicators that convey information about underlying protest attitudes, which may affect the respondents elicitation process. However, in all these cases, the identification of protestors is based on ad hoc criteria defined by the researcher, implying that respondents cannot be unambiguously identified as protesters.

In contrast, latent class models (LCM) can be used to endogenously identify classes of individuals with similar characteristics, such as preferences or atti- 
tudes, according to their responses to survey questions. ${ }^{1}$ In the context of $\mathrm{CV}$ studies, Bartczak, Liebe, and Meyerhoff [1] use a LCM to identify classes of protesters. The methodology followed by these authors only takes into account the responses to the attitudinal questions when estimating the latent classes. However, since the answers to the CV questions are directly affected by a respondent being a protestor or not, those answers could also be used to better infer about class membership, which is not the case in their paper.

We contribute to this literature by developing a LCM for estimating WTP using simultaneously $\mathrm{CV}$ and attitudinal data capturing protest attitudes. We also account for the presence of potential justification biases, that is, the possibility that for psychological reasons the response to the CV question affects the answers to the attitudinal questions, as suggested by Ben-Akiva, Walker, Bernardino, Gopinath, Morikawa, and Polydoropoulou [2]. This is different from all other studies, as to the best of our knowledge none has considered it before.

Our model is applied to a CV study regarding the preservation of the traditional landscape of the Douro Region, a recreation area in the north of Portugal, which has been classified by UNESCO as World Cultural Heritage since 2001, due to its unique natural and human environments. The estimation results obtained support the existence of two classes of respondents in the sample, identified as non-protesters and protesters.

The difference between the estimated values of WTP in the two classes captures the loss in potential contributions for providing the public good that can be imputed to the perceived lack of trust in public institutions responsible for environmental preservation. We propose using this difference as a measure of the implicit social cost. Thus, our article also contributes to the recent literature

\footnotetext{
${ }^{1}$ Recent examples of empirical applications of LCM based on different types of data are given by Walker and $\mathrm{Li}$ [22] on household location decisions, and Morey, Thacher, and Breffle [21], Breffle, Morey, and Thacher [5], and Bestard, Font, and Hicks [4] on recreational site choice.
} 
that discusses the impact of the quality of institutions on the efficient allocation of public goods (for example, the respect and enforcement of contracts, the efficacy of the rule of law, and the extent of government corruption), as in Bernauer and Koubi [3].

We also find a significant justification bias, that is, respondents bias their answers to the attitudinal questions when attempting to justify a "Not Pay" response to the $\mathrm{CV}$ question. It may be the case that a non-protester does not wish to look guilty in the eyes of other people for not affording to pay or not valuing the environment highly enough, and, subsequently, tries to justify his negative $\mathrm{CV}$ response by looking like a protestor when answering the attitudinal questions. If this justification bias is ignored in the model, some non-protester respondents are wrongly classified as protesters, and vice-versa, severely biasing both the estimate of the social cost and the economic value of the public good with implications for policy purposes. Therefore, we may conclude that psychological factors should not be ignored in CV estimation.

\section{The Model}

We present a model that describes the responses to the CV question and to a set of questions regarding protest attitudes. The responses to these attitudinal questions are used as protest indicators containing useful information about underlying unobserved attitudes toward protesting. We assume that the population can be divided into a finite number of classes $C$ that differ from each other in terms of their protest attitudes, which in turn affect the CV responses and the protest indicators. Therefore, although individual class membership is not directly observed, it can be inferred from the available data.

Figure 1 shows the general representation of the latent class model for WTP and protest attitudes using simultaneously CV and attitudinal data. It is based on the integrated choice and latent variable model proposed by Ben-Akiva et al. [2]. We present the particular case of two classes, denoted as protesters 
and non-protesters, as in the case of our application. Observed variables appear in rectangles while unobserved variables, such as WTP and the latent class variable, appear in ovals. The dashed arrows from the latent class variable to the protest indicators represent the measurement equations describing how the probability distributions of the protest indicators vary across classes. The solid lines represent the CV model. We also consider socio-economic variables as explanatory variables in the class membership equation and in the CV model. Finally, the model allows for justification bias, represented by the arrows that link the response to the $\mathrm{CV}$ question to the protest indicators.

In the dichotomous choice $\mathrm{CV}$ question, respondents were asked whether they would be willing to pay randomly assigned fixed amounts in order to preserve the environmental good, or prefer not to pay, in which case environmental preservation would be kept at a lower level (status-quo). To explain the responses to this question we follow the random WTP approach as described in Haab and McConnell [10]. The WTP for an individual $n$ belonging to a class $c$ is written as follows:

$$
\mathbf{W T P}_{n}^{c}=\mathbf{V}\left(\mathbf{Z}_{n}, \boldsymbol{\vartheta}_{n}^{c} ; \boldsymbol{\alpha}^{c}\right)
$$

where $\mathbf{Z}_{n}$ is a $k \times 1$ vector of explanatory variables that reflect individualspecific socio-economic characteristics, $\boldsymbol{\vartheta}_{n}^{c}$ is a stochastic component capturing other unobservable individual heterogeneity, and $\boldsymbol{\alpha}^{c}$ is a vector of parameters specific to each class $c=1, \ldots, C$. Assuming a log-linear model, we have that, conditional on the individual belonging to class $c$,

$$
\ln \left(\mathbf{W T P}_{n}^{c}\right)=\boldsymbol{\alpha}^{c} \mathbf{Z}_{n}+\boldsymbol{\vartheta}_{n}^{c}
$$

In the particular case of two classes, where one represents protesters and the other non-protesters, equation (2) would correspond to the true economic WTP for the non-protester class. For protesters, it would in general be different from 
the WTP from utility maximization. In our application, we adopt the usual logit model and assume that $\boldsymbol{\vartheta}_{n}^{c} / \sigma^{c}$ follows a standard logistic distribution where $\sigma^{c}$ is a scale parameter affecting the variance of the stochastic term in class $c$ such that the cumulative distribution function of $z \equiv \boldsymbol{\vartheta}_{n}^{c} / \sigma^{c}$ is given by $\mathbf{F}(z)=e^{z} /\left(1+e^{z}\right)$.

It follows that an individual responds to the CV question with "Pay" or "Not Pay" if his WTP is "larger" or "not larger" than the proposed bid amount, respectively. Defining $u_{n}=1$ when the response is "Pay", and $u_{n}=0$ when it is "Not Pay", we have that:

$$
u_{n}=\left\{\begin{array}{cc}
1 & \text { if } \mathbf{W T P}_{n}^{c}>\operatorname{Bid}_{n} \\
0 & \text { otherwise }
\end{array}\right.
$$

where $\operatorname{Bid}_{n}$ is the randomly proposed bid amount. Therefore, the probability that an individual $n$ belonging to class $c$ chooses to pay is given by:

$$
\mathbf{P}\left(u_{n}=\mathbf{1} \mid \mathbf{Z}_{n}, \operatorname{Bid}_{n}, c\right)=\mathbf{F}\left(\boldsymbol{\beta}_{1}^{c} \mathbf{Z}_{n}+\beta_{2}^{c} \ln \left(\operatorname{Bid}_{n}\right)\right)
$$

where $\boldsymbol{\beta}_{1}^{c}=\boldsymbol{\alpha}^{c} / \sigma^{c}$, and $\beta_{2}^{c}=-1 / \sigma^{c}$. The median WTP for an individual in class $c$ is given by $\operatorname{Med}\left(\mathbf{W} \mathbf{T P}_{n}^{c}\right)=\exp \left[\left(\boldsymbol{\beta}_{1}^{c} \mathbf{Z}_{n}\right) /\left(-\beta_{2}^{c}\right)\right]$.

The responses to the $p$ attitudinal questions are denoted by a $p \times 1$ vector $\mathbf{I}_{n}$ $=\left(\mathrm{I}_{n 1}, \ldots, \mathrm{I}_{n p}\right)^{\prime}$ of protest indicators. These indicators are categorically-ordered variables, where responses are given on a Likert scale, taking values from 1 to $T$, as follows. For any given protest indicator $j=1, \ldots, p$, we have that

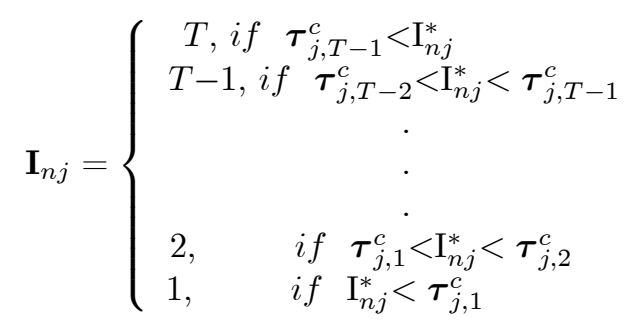

where $\boldsymbol{\tau}_{j, k}^{c}$ represents the threshold of switching from category $k-1$ to category $k$ when an individual belongs to class $c$, and $\mathbf{I}_{n j}^{*}$ represents in this case the corresponding latent unobserved indicator. We denote by $\boldsymbol{\tau}^{c}$ the vector of all $\boldsymbol{\tau}_{j, k}^{c}, j=1, \ldots, p, k=1, \ldots, T-1$. 
The latent protest indicators are assumed to depend on the class $c$, on the explanatory variables $\mathbf{Z}_{n}$, and on the response to the CV question $\mathbf{u}_{n}$, capturing the justification bias, according to the measurement equation:

$$
\mathbf{I}_{n}^{*}=\Theta^{c} \mathbf{Z}_{n}+\Psi_{n}^{c} u_{n}+\varepsilon_{n}^{c}
$$

where $\Theta^{c}$ and $\Psi^{c}$ are $p \times k$ and $p \times 1$ vectors of parameters, respectively, for class $c$, and $\varepsilon_{n}^{c}$ is a $p \times 1$ vector of error terms that follows some distribution denoted as $D\left(0, \Sigma_{\varepsilon}^{c}\right)$ with parameters $\Sigma_{\varepsilon}^{c}$, which may vary across classes. In our application we assume a logistic distribution. In the questionnaire used in our empirical application, as is common in related studies, the attitudinal questions appear immediately after the CV question. If the order of the questions was reversed, the nature of the justification bias would also have to be changed and the model modified accordingly.

From equations (5) and (6) we derive the probability of individual $n$ responding $\mathbf{I}_{n}$ conditional on belonging to a particular class $c$, having characteristics $\mathbf{Z}_{n}$, and having responded $u_{n}$ to the CV question, which is denoted as $\mathbf{g}\left(\mathbf{I}_{n} \mid \mathbf{Z}_{n}, u_{n}, c\right)$.

Finally, we also allow class membership to depend on explanatory variables:

$$
\mathbf{P}\left(c_{n}=c \mid \mathbf{Z}_{n}\right)=\frac{e^{\delta^{c}+\gamma^{c} \mathbf{Z}_{n}}}{\sum_{c=1}^{C} e^{\delta^{c}+\gamma^{c} \mathbf{Z}_{n}}} \quad \text { for } c=1, \ldots, C .
$$

Equation (7) represents the probability that individual $n$ belongs to class $c$ given his socio-economic characteristics.

The joint probability of the responses to the CV and protest indicators, conditional only on the observable explanatory variables, is then given by

$$
\begin{gathered}
\mathbf{f}\left(\mathbf{I}_{n}, u_{n} \mid \mathbf{Z}_{n}, \operatorname{Bid}_{n}\right)= \\
\sum_{c=1}^{C} \prod_{i=0,1} \mathbf{1}\left(u_{n}=i\right) \mathbf{P}\left(u_{n}=i \mid \mathbf{Z}_{n}, \operatorname{Bid}_{n}, c\right) \mathbf{g}\left(\mathbf{I}_{n} \mid \mathbf{Z}_{n}, u_{n}, c\right) \mathbf{P}\left(c_{n}=c \mid \mathbf{Z}_{n}\right)
\end{gathered}
$$


where $1(\cdot)$ denotes the indicator function. The maximum likelihood estimator of the parameters of this model are then obtained by

$$
\max _{\theta} \mathbf{L}(\boldsymbol{\theta})=\max _{\theta}\left(\prod_{n=1}^{N} \mathbf{f}\left(\mathbf{I}_{n}, u_{n} \mid \mathbf{Z}_{n}, \operatorname{Bid}_{n}\right)\right)
$$

where $\boldsymbol{\theta}=\left\{\left(\boldsymbol{\beta}_{1}^{c}, \boldsymbol{\beta}_{\mathbf{2}}^{\mathbf{c}}, \Theta^{\mathbf{c}}, \Psi^{c}, \Sigma_{\varepsilon}^{c}, \boldsymbol{\tau}^{\mathbf{c}}, \delta^{c}, \boldsymbol{\gamma}^{c}\right), c=1,2, \ldots, C\right\}$ and $N$ denotes the number of observations in the sample. The estimations were performed using the EM algorithm (see Dempster, Laird, and Rubin [8]). ${ }^{2}$

\section{Case Study}

Our empirical application was based on a survey conducted in The Alto Douro Wine Region, located to the east of the city of Oporto, in the north of Portugal. The cultural landscape of the Alto Douro represents an outstanding example of humankind's unique relationship with the natural environment. The "Demarcated Douro Region", defined and regulated since 1756, is one of the oldest of all the historic winemaking regions in the world, producing a world commodity, Port Wine, famous for its quality around the globe. The building of its landscape pattern by the wine producers, characterized by the land partition and cultural diversity, was recognized as an exceptional testimony to a living cultural tradition, and the Alto Douro Wine Region became part of UNESCO's World Heritage cultural landscape in 2001.

In the last three decades, there has been an enormous pressure to transform the old vineyards into modern ones with the associated destruction of the typical landscape, due to the need of increasing productivity. In this context, we investigate the possibility of using tax revenues to financially support the winegrowers in the region to prevent the destruction of the landscape. ${ }^{3}$ However, the extent to which citizens trust public institutions responsible for the implementation of this project is a crucial issue in this context.

\footnotetext{
${ }^{2}$ The code to implement the estimations is available from the authors upon request.

${ }^{3}$ This is a quasi-public good, because it is possible to exclude people from its use, by charging a price to use the resource or making the agent spend money or time to use the resource.
} 
Recent evidence shows that income per capita or its growth, as well as the achievements in the areas of health, education, infrastructure, etc., are highly correlated with measures of institutional quality, ranging between 0.65 and 0.78 , as mentioned in Gradstein [9]. A variety of institutional quality measures have been developed. For example, Kaufmann, Kraay, and Mastruzzi [15] have constructed aggregate measures of governance for 209 countries and territories for five recent years, including voice and accountability; political instability and violence; government effectiveness; regulatory quality; rule of law; and control of corruption. In particular, in the index on Government Effectiveness, the authors "...combine responses on the quality of public service provision, the quality of the bureaucracy, the competence of civil servants, the independence of the civil service from political pressures, and the credibility of the government's commitment to policies. The main focus of this index is on inputs required for the government to be able to produce and implement good policies and deliver public goods." 4

In the case of Portugal, for the period considered (1996-2004), the index does not show an improvement in the country's relative position. On the contrary, from 2002 to 2004, it shows a negative trend. ${ }^{5}$ In general, Portugal is closer to the southern European countries than to the Nordic ones. Spain is typically ahead of Portugal, while Portugal is ahead of Greece. In the last decade, the persistence of a large budget deficit has been responsible for a long period of slow growth, below the EU average, making convergence more difficult. Since there is also recent evidence that shows a great deal of persistence in indicators related to development, such as income, growth rates, and income inequality, as well as with respect to institutional indicators, and given the performance of the Portuguese economy in recent years, a reversal of the observed trend is not

\footnotetext{
${ }^{4}$ See Kaufmann, Kraay, and Mastruzzi [15], pg. 130.

${ }^{5}$ See Kaufmann, Kraay, and Mastruzzi [15], pg. 123.
} 
expected.

\section{The Data}

Information was collected in the summer of 2006 through face-to-face interviews of a random sample of visitors to the Alto-Douro Wine region. Interviewers followed a worded script to avoid leading effects. The questionnaire included a CV question to measure the WTP for landscape preservation. The CV question format chosen was the referendum dichotomous choice. Each respondent was asked a CV question for an improvement in the level of preservation where the status-quo was the case of no preservation, and the bids varied randomly among the respondents. The payment mechanism that was proposed to respondents was an annual payment that would be collected in addition to the annual income tax. The money raised would go to a public institution that would compensate winegrowers for the incurred costs to keep the traditional landscape.

Moreover, attitudinal questions were also included in the survey immediately following the CV question, and all respondents were asked to answer them. These questions, presented in the Appendix, are similar to those used in other studies investigating protest responses (see Jorgensen et al. [14] and Jorgensen and Syme [13]) and include not only the standard motivations for protesting, but also other reasons for paying (attitudes toward the environment) or not paying (budget constraints). The answers were given on a five-level Likert scale (from 1-strongly disagree to 5-strongly agree).

The sample used in this article consists of 706 observations. Table 1 provides descriptive statistics for all the variables used in the estimations.

\section{Estimation Results}

In Table 2, we present the results of an exploratory factor analysis of the responses to all attitudinal questions. The factor loadings for the first three factors are presented. The first factor has high loads for questions 1, 2, 3, 6, and 9, all of which concern mostly budget constraint issues. The five questions that have 
a factor loading larger than 0.5 for the second factor are questions $4,5,8,10$, and 11. We interpret these questions as reflecting protest attitudes related to the lack of trust in public institutions and their role in the provision of public goods. The third factor is related to questions $12,13,14$, and 15 , which reflect a positive valuation of environmental preservation.

Based on these results, we select the responses to the attitudinal questions related to the second factor as protest indicators that will be used in our application. The corresponding frequency distributions appear in Table 3. For all protest indicators, the responses are mostly concentrated in the range 3-5 with a mode of 4 , meaning that most people were either indifferent or agreed with the statements.

Next, we present and discuss the estimation results for the model presented above. In order to decide on the number of classes, we use the Lo-MendellRubin (LMR) adjusted likelihood ratio test (see Lo, Mendell, and Rubin [16]), a parametric bootstrap test (see McLachlan and Peel [17]), and other criteria such as BIC, adjusted BIC, and AIC. The results support the existence of two classes against one. ${ }^{6}$

Estimation results for the models with two classes appear in Table 4. While Model 1J allows for justification bias, Model 1 does not. This table is divided into four sections. The first corresponds to the CV equation (4), the second to the justification bias effect in the measurement equation (6), and the third to the class membership equation (7). Finally, the estimated median WTP and the estimated proportion of individuals in each class, as well as other model fit

\footnotetext{
${ }^{6}$ Some identification problems affected the estimated model with 3 classes which may invalidate the corresponding likelihood ratio test (see Lo et al. [16] and McLachlan and Peel $[17]$ ). Even after fixing some of the parameters, standard errors could not be computed due to a non-positive definite first-order derivative product matrix. The reason for this is that in this type of model with 3 or more classes, the number of parameters to estimate becomes very large, and unless the sample is very large, there will always be a chance that some of the intervals defined in (5) have no observations. The likelihood ratio tests selected 3 classes while the BIC selected 2 classes. Given the overparametrization of the model with 3 classes, the preferred model was the one with only 2 classes.
} 
statistics are shown in the fourth part at the bottom of the table. According to all model selection criteria, as presented in Table 4, and a likelihood ratio test, Model 1J, allowing for justification bias, is preferred. Moreover, the majority of the coefficients capturing this effect are significant in both classes.

We have also computed for each model the probability distributions of the protest indicators for each class and, in the case of Model 1J, for each possible response to the CV question. These are presented in Table 5. To facilitate the reading of the results, for each protest indicator, the probabilities of indicating levels $4-5$ in the Likert scale for Models 1 and $1 \mathrm{~J}$ are presented graphically in Figures 2 and 3, respectively.

For both models, the two classes differ with respect to the estimated coefficients in the CV model, as well as in the probability distributions of the protest indicators. In addition, in Model $1 \mathrm{~J}$, there are also differences in the way the response to the $\mathrm{CV}$ model impacts the protest indicators, that is, the two classes differ in terms of the justification bias.

For Model 1, we may conclude from the results in Table 5 that the probability distribution of the protest indicators for class 1 is shifted to the right relative to class 2 , meaning that respondents in the first class have stronger attitudes toward protesting. This is clear from Figure 2, where we observe that the respondents of class 1 have a higher probability of indicating levels 4 and 5 in the Likert scale for all protest indicators in comparison with those in class 2 . In Model 1J this conclusion also holds if we control for the response to the CV question (see also Figure 3). Consequently, we interpret class 1 as representing protesters and class 2 non-protesters.

We also allow for the socio-economic characteristics to affect class membership. In particular, age has a negative impact and employment condition has a positive one. Therefore, younger people with a job have a higher probability of belonging to the protester class. 
In Model 1J, the negative signs of the estimates of the coefficients associated with the answer to the $\mathrm{CV}$ in the measurement equation (see the second part of Table 4) mean that responding "Pay" to the CV question has a negative impact on the levels of the protest indicators in both classes. Therefore, we can conclude that, in both classes, when a respondent answers negatively to the CV question, that person tries to justify that response by positively biasing his responses to the protest indicators. This effect is clear from Figure 3. The justification bias can be regarded as an "attribution bias" due to psychological reasons. ${ }^{7}$ For instance, it may be the case that a non-protester does not wish to look guilty in the eyes of other people for not affording to pay or not valuing the environment highly enough, and, subsequently, tries to justify his negative CV response by giving higher values to the protest indicators, that is, he tries to look like a protester although it is not the case.

Regarding the CV part of the model, the estimated coefficients of $\ln (\mathrm{Bid})$ are significant and have the expected negative sign in both models, 1 and 1J. We also sought to include other explanatory variables but none were significant. The median WTP is computed for each class. We conclude from Model 1J (see Table 4) that the WTP is greater for the non-protester class, 13.4 euros, than for the protester class, 8 euros. $^{8}$ The difference between the two values, 5.4 euros, captures the loss in potential contributions to support the provision of the local public good in the Douro region due to the presence of protesters, which corresponds to about $25 \%$ of the individuals in the sample (see Table 4 ).

Thus, if this sample was representative of the population, the estimated loss of 5.4 euros for about a quarter of the population could be taken as a lower bound to the social cost of having institutions that are inefficient at providing

\footnotetext{
${ }^{7}$ In Psychology, an "attributional bias" is a cognitive bias that affects the way an individual determines who or what was responsible for an event or action (attribution).

${ }^{8}$ For a simple logit model with just one class, the corresponding estimated median WTP is approximately 10 euros, which falls between those values, as expected.
} 
this local public good, as perceived by the population. ${ }^{9}$ Note that the estimated social cost is computed as a difference between two classes, and it is possible that respondents in class 2 , with a weaker attitude toward protesting relative to class 1, also exhibit protest responses such that the measure of WTP in this class may be undervalued. Ultimately, the optimal decision on the provision of the local public good at stake should be supported by a cost-benefit analysis that would ideally also take into account the costs incurred by wine producers to maintain the traditional landscape.

Finally, we observe that, if no justification bias is allowed for as in Model 1, the estimated median WTP for the non-protestor class becomes higher (17.8 vs 13.4 euros) and lower for the protester class (6.4 vs 8 euros), implying that the difference between the WTP in the two classes becomes much larger (11.4 vs 5.4 euros). Intuitively, this discrepancy is caused by the fact that in this model some individuals are wrongly classified as protesters because they are "inflating" their responses to the attitudinal questions while attempting to justify a "Not Pay" response to the CV question. Therefore, in the preferred model, Model 1J, for those respondents who chose not to pay, the probability of being classified as a protester is reduced relative to Model 1, which does not allow for the justification bias. Hence, in Model $1 \mathrm{~J}$, these individuals can be reclassified as non-protesters. As a result, more people who responded "Not Pay" end up in the non-protester class, and vice-versa for those who have responded "Pay", so that we end up with more payers in the protester class and non-payers in the non-protester class. Thus, we conclude that, if justification bias was not considered, it would lead to an overestimation of both the economic value of the public good and the social cost of the perceived inefficiency of public institutions in providing that good.

\footnotetext{
${ }^{9}$ In general, in order to obtain an aggregate estimate of the cost for society, heterogeneity in the population should be taken into account.
} 


\section{Conclusions}

In this article, we develop a latent class model for estimating WTP for public goods using simultaneously CV and attitudinal data capturing protest attitudes related to the lack of trust in public institutions providing those goods. Based on a CV study conducted in The Alto Douro Wine Region, located in the north of Portugal, two classes of respondents are identified, protestors and nonprotestors, and its impact on the estimated WTP is examined.

We propose a measure of the social cost associated with the lack of perceived credibility of public institutions responsible for the provision of the public good, by computing the difference between the WTP estimates in the two classes. Such a measure may be important for policy purposes, as it provides an estimate of the loss in potential contributions to support the provision of the local public good. Moreover, we allow for the possibility of a justification bias, that is, the potential impact of the response to the CV question on the answers to the attitudinal questions. We show that omitting this justification bias would overestimate the economic value of the public good and more than double the estimate of the social cost related to the mistrust in public institutions, with important policy implications. Therefore, psychological factors should not be disregarded in $\mathrm{CV}$ estimation, allowing for a correct identification of protest responses.

Our methodology is flexible enough, and can be applied to other cases where mistrust of institutions or other sources of inefficiency may have an impact on the provision of public goods. Moreover, it is possible to extend the latent class model by incorporating additional latent variables to capture different types of attitudes. This is left for further research. 


\section{References}

[1] Bartczak, A., U. Liebe, and J. Meyerhoff, "Identifying Various Types of Protesters in Contingent Valuation Using Latent Class Analysis", mimeo, 2009.

[2] Ben-Akiva, M., J. Walker, A. Bernardino, D. Gopinath, T. Morikawa, and A. Polydoropoulou, "Integration of Choice and Latent Variable Models", mimeo, 1999.

[3] Bernauer, T., and V. Koubi, "Effects of Political Institutions on Air Quality", Ecological Economics 68:1355-1365, 2009.

[4] Bestard, A., A. Riera Font, and R. Hicks, "Combining Discrete and Continuous Representations of Preference Heterogeneity: A Latent-Class Approach", mimeo, 2009.

[5] Breffle, W., E. Morey, and J. Thacher, "Full Information Maximum Likelihood Estimation of Heterogeneous Preferences with Choice Data and Other Preference Statements", mimeo, 2008.

[6] Carson, R., T. Groves, "Incentive and Informational Properties of Preference Questions", Environmental \& Resource Economics 31:181-210, 2007.

[7] Dziegielewska, D., and R. Mendelsohn, "Does "No" Means "No"? A Protest Methodology", Environmental \& Resource Economics 38:71-87, 2007.

[8] Dempster, A. P. , N. M. Laird, and D. B. Rubin, "Maximum Likelihood from Incomplete Data via the EM Algorithm", Journal of the Royal Statistical Society, Series B, 39: 1-38, 1977.

[9] Gradstein, M., "Institutional Traps and Economic Growth", International Economic Review 49:1043-1066, 2008. 
[10] Haab, T., and K. McConnell, "Valuing Environmental and Natural Resources", Edward Elgar, UK, 2002.

[11] Jakobsson, K., and A. Dragun, "The Worth of a Possum: Valuing Species with the Contingent Valuation Method", Environmental \& Resource Economics 19: 211-227, 2001.

[12] Johnston, R., and J. Duke, "Willingness to pay for Agricultural Land Preservation and Policy Process Attributes: Does the Method Matter?", American Journal of Agricultural Economics 89(4): 1098-1115, $200 \%$.

[13] Jorgensen, B., and G. Syme "Protest Responses and Willingness to Pay: Attitude Toward Paying for Storm Water Pollution Abatement", Ecological Economics 33(2):251-265, 2000.

[14] Jorgensen, B., G. Syme, B. Bishop, and B. Nancarrow, "Protest Responses in Contingent Valuation", Environmental \& Resource Economics 14(1), 131-150, 1999.

[15] Kaufmann, D., A. Kraay, and M. Mastruzzi, "Governance Matters IV: Governance Indicators for 1996-2004", mimeo, World Bank, Washington DC, 2005.

[16] Lo, Y., N.R. Mendell, and D.B. Rubin, "Testing the Number of components in a Normal Mixture", Biometrika 88: 767-778, 2001.

[17] McLachlan, G.J., and D. Peel, "Finite Mixture Models", Wiley, New York, 2000.

[18] Meyerhoff, J., and U. Liebe, "Protest responses in Contingent Valuation: Explaining Their Motivation", Ecological Economics 57:583-594, 2006. 
[19] Meyerhoff, J., and U. Liebe, "Do protest Responses to a Contingent Valuation Question and a Choice Experiment Differ?", Environmental \& Resource Economics 39:433-446, 2008.

[20] Mitchell, R.C., and R.T. Carson, "Using Surveys to Value Public Goods: The Contingent Valuation Method", Resources for the Future, Washington, DC, 1989 .

[21] Morey, E., J. Thacher, and W. Breffle, "Using Angler Characteristics and Attitudinal Data to Identify Environmental Preference Classes: A LatentClass Model", Environmental \& Resource Economics 34:91-115, 2006.

[22] Walker, J., and J. Li, "Latent Lifestyle Preferences and Household Location Decisions", mimeo, 2007. 


\section{Appendix:}

\section{Attitudinal Questions}

Q1. The values are too high

Q2. I can't afford to pay anything right now

Q3. The landscape preservation is not my problem

Q4. The landscape should be preserved with the current taxes

Q5. I think the money will be used for other purposes

Q6. The residents of the region should pay for this preservation

Q7. The local authorities and tourist operators should pay for this preservation

Q8. It is not fair to ask me to pay

Q9. I would rather pay for more important things

Q10. This payment will not insure the preservation of the landscape

Q11. I already pay enough taxes for this preservation

Q12. It is necessary to pay to visit and benefit from this region more often

Q13. It is necessary to pay to insure the preservation of this landscape because it is unique

Q14. It is necessary to pay to insure the preservation of this landscape because it is beautiful

Q15. It is necessary to pay to insure the preservation of nature and biodiversity in this region

Likert Scale used:

1- strongly disagree

2- disagree

3- neither agree nor disagree

4- agree

5- strongly agree 
Table 1: Descriptive Statistics

\begin{tabular}{|lccccll|}
\hline Variable & Mean & SD & Min & Max & Description \\
\hline \multicolumn{2}{l}{ CV Response } & 0.32 & 0.47 & 0 & 1 & Response to the CV question (1=Pay, 0=Not Pay) \\
Bid & 46.7 & 29.7 & 10 & 100 & Bid for the CV question in Euros \\
Age & 45.3 & 13.7 & 18 & 85 & Age of the respondent \\
Emp & 0.78 & 0.41 & 0 & 1 & Employment Condition (1=Employed, $0=$ otherwise) \\
\hline
\end{tabular}

Table 2: Factor Loadings from an exploratory factor analysis of the responses to the attitudinal questions

\begin{tabular}{|l|c|c|c|}
\hline \multirow{2}{*}{$\begin{array}{l}\text { Attitudinal } \\
\text { Questions }\end{array}$} & \multicolumn{3}{|c|}{ Factors } \\
\cline { 2 - 4 } & $1^{\text {st }}$ & $2^{\text {nd }}$ & $3^{\text {rd }}$ \\
\hline Q1 & $\mathbf{0 . 3 4 4}$ & 0.161 & -0.079 \\
\hline Q2 & $\mathbf{0 . 7 1 3}$ & -0.004 & 0.09 \\
\hline Q3 & $\mathbf{0 . 5 5 4}$ & 0.192 & 0.006 \\
\hline Q4 & -0.261 & $\mathbf{0 . 5 0 6}$ & -0.011 \\
\hline Q5 & 0.014 & $\mathbf{0 . 6 6 9}$ & 0.044 \\
\hline Q6 & $\mathbf{0 . 4 3 2}$ & -0.052 & 0.181 \\
\hline Q7 & -0.09 & 0.184 & 0.044 \\
\hline Q8 & 0.182 & $\mathbf{0 . 6 3 1}$ & -0.044 \\
\hline Q9 & $\mathbf{0 . 3 4 2}$ & 0.187 & -0.152 \\
\hline Q10 & 0.005 & $\mathbf{0 . 7 7 7}$ & 0.019 \\
\hline Q11 & -0.045 & $\mathbf{0 . 7 4}$ & 0.072 \\
\hline Q12 & 0.006 & 0.027 & $\mathbf{0 . 9 3 3}$ \\
\hline Q13 & -0.008 & -0.02 & $\mathbf{0 . 9 6 2}$ \\
\hline Q14 & 0.016 & 0.012 & $\mathbf{0 . 9 7 4}$ \\
\hline Q15 & -0.008 & -0.012 & $\mathbf{0 . 9 6 2}$ \\
\hline
\end{tabular}

Table 3: Distribution of responses to the attitudinal questions (in \%).

\begin{tabular}{|l|c|c|c|c|c|}
\hline \multirow{2}{*}{$\begin{array}{c}\text { Attitudinal } \\
\text { Questions }\end{array}$} & \multicolumn{5}{|c|}{ Likert Scale } \\
\cline { 2 - 6 } & 1 & 2 & 3 & 4 & 5 \\
\hline Q4 & 0.4 & 3.8 & 7.1 & 60.9 & 27.8 \\
\hline Q5 & 1.1 & 10.8 & 28.9 & 41.5 & 17.7 \\
\hline Q8 & 1.4 & 15.4 & 15.6 & 52.1 & 15.4 \\
\hline Q10 & 0.6 & 12.5 & 31.6 & 38.2 & 17.1 \\
\hline Q11 & 0.7 & 5.4 & 12.3 & 54.4 & 27.2 \\
\hline
\end{tabular}


Table 4: Estimation Results

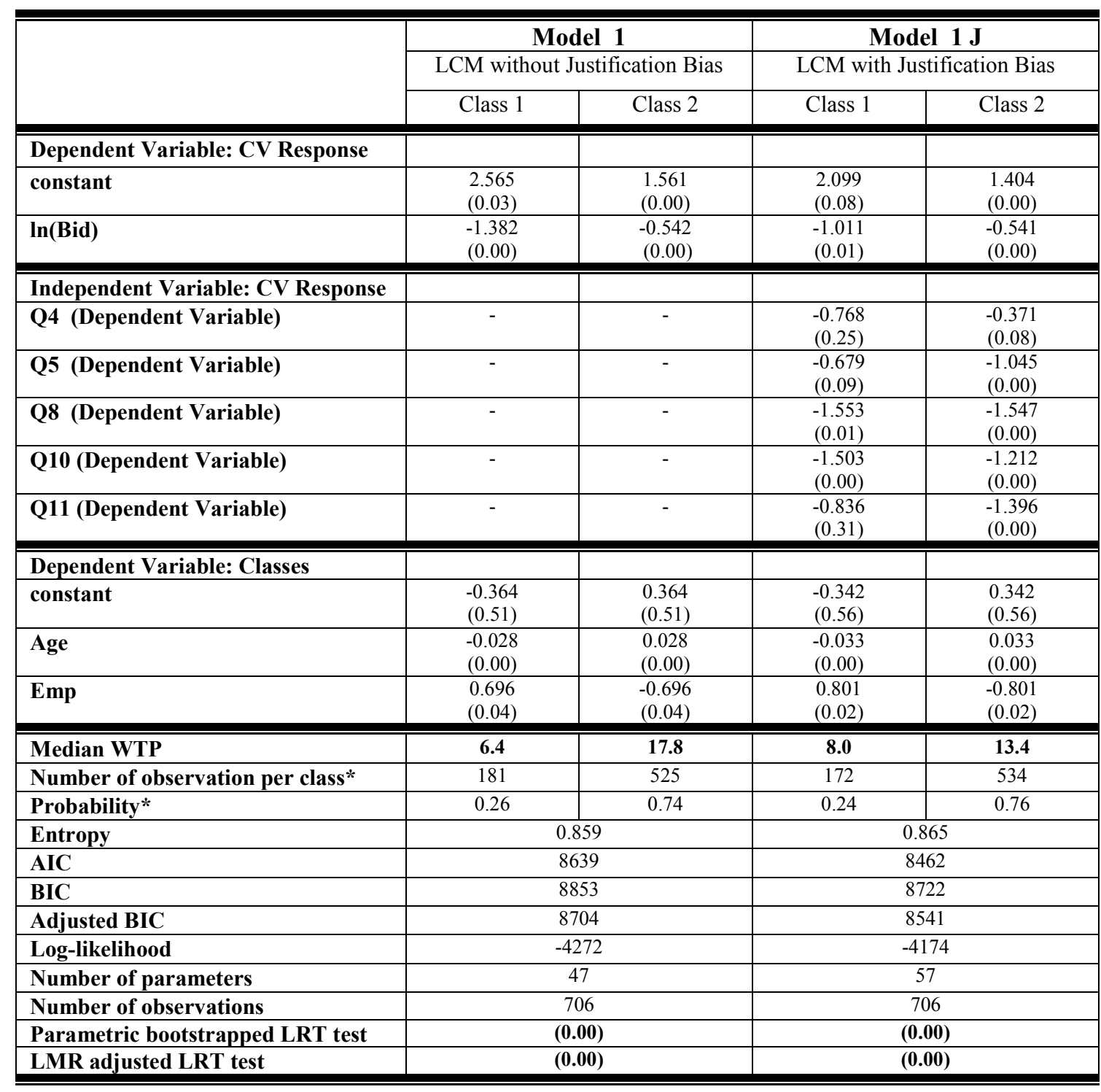

Notes: p-values appear in parentheses. WTP is in Euros.

*The number of observations per class and corresponding probabilities are based on the individual posterior probabilities of belonging to each class conditional on the observed variables. 
Table 5: Estimated conditional probabilities of responses to the attitudinal questions (in \%)

\begin{tabular}{|l|l|r|r|r|r|r|r|}
\hline & & \multicolumn{2}{|c|}{ Model 1 } & \multicolumn{4}{|c|}{ Model 1 J } \\
\hline & & Class 1 & \multicolumn{1}{|c|}{ Class 2 } & \multicolumn{2}{|c|}{ Class 1 } & \multicolumn{2}{c|}{ Class 2 } \\
& & & & \multicolumn{1}{l|}{ Not Pay } \\
\hline Q4 & $\operatorname{Pr}(\mathrm{Q} 4=1 \mid$ Class $)$ & 1.6 & 0 & 1.4 & 3 & 0 & 0 \\
\hline & $\operatorname{Pr}(\mathrm{Q} 4=2 \mid$ Class $)$ & 0 & 5.2 & 0.5 & 1 & 4.2 & 6.0 \\
\hline & $\operatorname{Pr}(\mathrm{Q} 4=3 \mid$ Class $)$ & 0.4 & 9.5 & 0.9 & 1.8 & 8.0 & 10.8 \\
\hline & $\operatorname{Pr}(\mathrm{Q} 4=4 \mid$ Class $)$ & 26.1 & 73.7 & 18.9 & 31.5 & 74.5 & 73.7 \\
\hline & $\operatorname{Pr}(\mathrm{Q} 4=5 \mid$ Class $)$ & 71.9 & 11.5 & 78.4 & 62.7 & 13.3 & 9.5 \\
\hline Q5 & $\operatorname{Pr}(\mathrm{Q} 5=1 \mid$ Class $)$ & 2.1 & 0.8 & 2.0 & 3.9 & 0.4 & 0.8 \\
\hline & $\operatorname{Pr}(\mathrm{Q} 5=2 \mid$ Class $)$ & 0.2 & 14.7 & 0 & 0 & 9.5 & 22.6 \\
\hline & $\operatorname{Pr}(\mathrm{Q} 5=3 \mid$ Class $)$ & 10.7 & 35.6 & 8.8 & 15.3 & 30.9 & 42.4 \\
\hline & $\operatorname{Pr}(\mathrm{Q} 5=4 \mid$ Class $)$ & 35 & 43.9 & 30.7 & 39 & 52.5 & 31.3 \\
\hline & $\operatorname{Pr}(\mathrm{Q} 5=5 \mid$ Class $)$ & 52 & 5.1 & 58.5 & 41.7 & 6.8 & 2.5 \\
\hline Q8 & $\operatorname{Pr}(\mathrm{Q} 8=1 \mid$ Class $)$ & 2.4 & 1 & 2.0 & 8.6 & 0.3 & 1.5 \\
\hline & $\operatorname{Pr}(\mathrm{Q} 8=2 \mid$ Class $)$ & 2 & 20.4 & 3.1 & 11.6 & 10.2 & 34.2 \\
\hline & $\operatorname{Pr}(\mathrm{Q} 8=3 \mid$ Class $)$ & 3.4 & 20.1 & 2.9 & 8.8 & 15.3 & 26.4 \\
\hline & $\operatorname{Pr}(\mathrm{Q} 8=4 \mid$ Class $)$ & 46.2 & 54.3 & 41.5 & 53.2 & 66.1 & 36.1 \\
\hline & $\operatorname{Pr}(\mathrm{Q} 8=5 \mid$ Class $)$ & 45.9 & 4.2 & 50.5 & 17.8 & 8 & 1.8 \\
\hline Q10 & $\operatorname{Pr}(\mathrm{Q} 10=1 \mid$ Class $)$ & 0.5 & 0.6 & 0.4 & 1.5 & 0.3 & 1.3 \\
\hline & $\operatorname{Pr}(\mathrm{Q} 10=2 \mid$ Class $)$ & 1.8 & 16.4 & 1.4 & 5.8 & 9.6 & 26 \\
\hline & $\operatorname{Pr}(\mathrm{Q} 10=3 \mid$ Class $)$ & 5.4 & 41.2 & 2.9 & 10.6 & 36.5 & 47.4 \\
\hline & $\operatorname{Pr}(\mathrm{Q} 10=4 \mid$ Class $)$ & 33 & 40.2 & 24.8 & 47.3 & 51.3 & 24.9 \\
\hline & $\operatorname{Pr}(\mathrm{Q} 10=5 \mid$ Class $)$ & 59.3 & 1.6 & 70.6 & 34.8 & 2.3 & 0.7 \\
\hline Q11 & $\operatorname{Pr}(\mathrm{Q} 11=1 \mid$ Class $)$ & 1 & 0.6 & 0.9 & 2.1 & 0.3 & 0.6 \\
\hline & $\operatorname{Pr}(\mathrm{Q} 11=2 \mid$ Class $)$ & 0 & 7.4 & 0.7 & 1.6 & 3.5 & 12.6 \\
\hline & $\operatorname{Pr}(\mathrm{Q} 11=3 \mid$ Class $)$ & 1.2 & 16.4 & 1.8 & 3.9 & 9.9 & 25.4 \\
\hline & $\operatorname{Pr}(\mathrm{Q} 11=4 \mid$ Class $)$ & 19 & 67.4 & 12.6 & 23.1 & 73.7 & 57.4 \\
\hline & $\operatorname{Pr}(\mathrm{Q} 11=5 \mid$ Class $)$ & 78.8 & 8.2 & 83.9 & 69.4 & 12.6 & 3.4 \\
\hline & & & & & & & \\
\hline
\end{tabular}




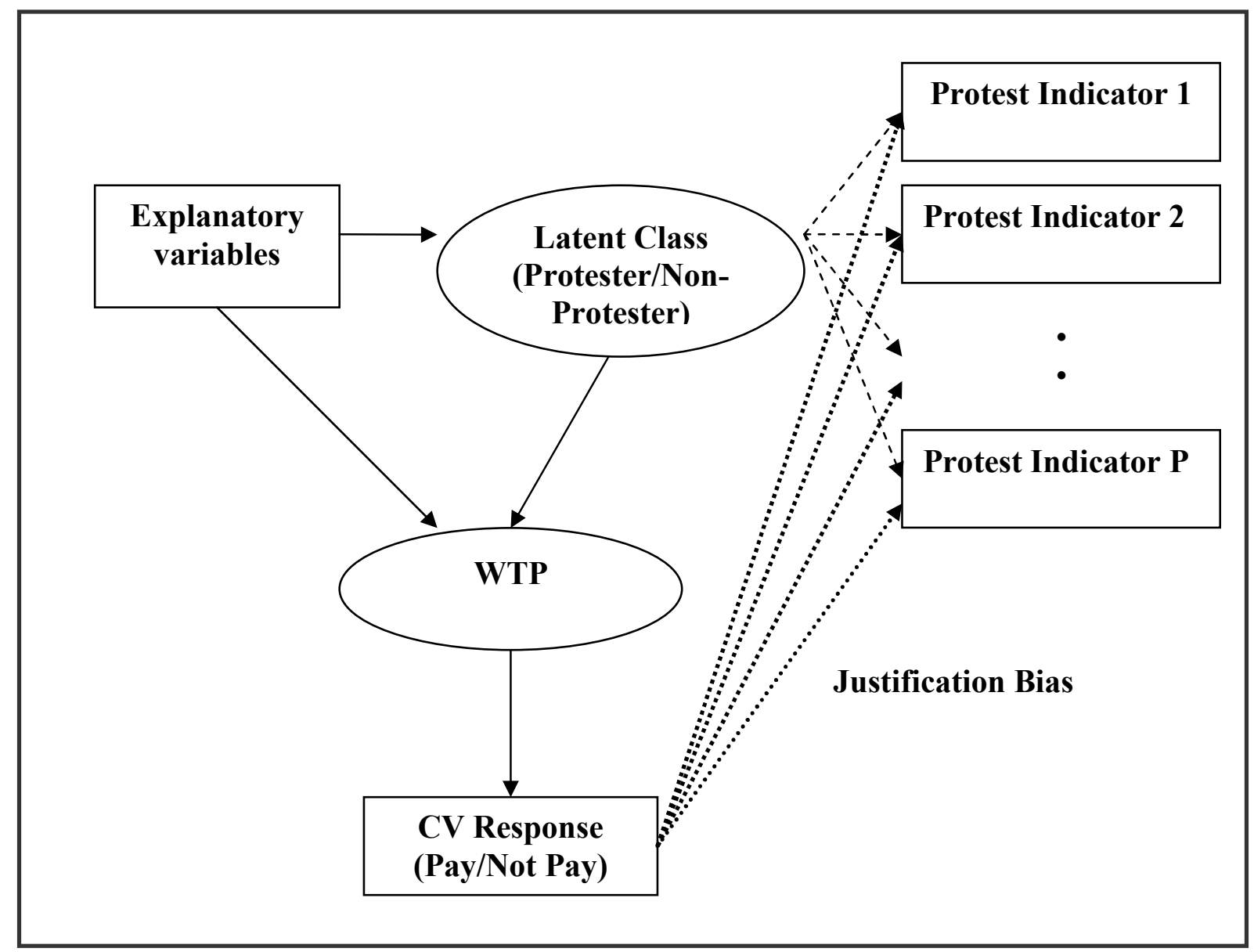

Figure 1. General representation of the latent class model 


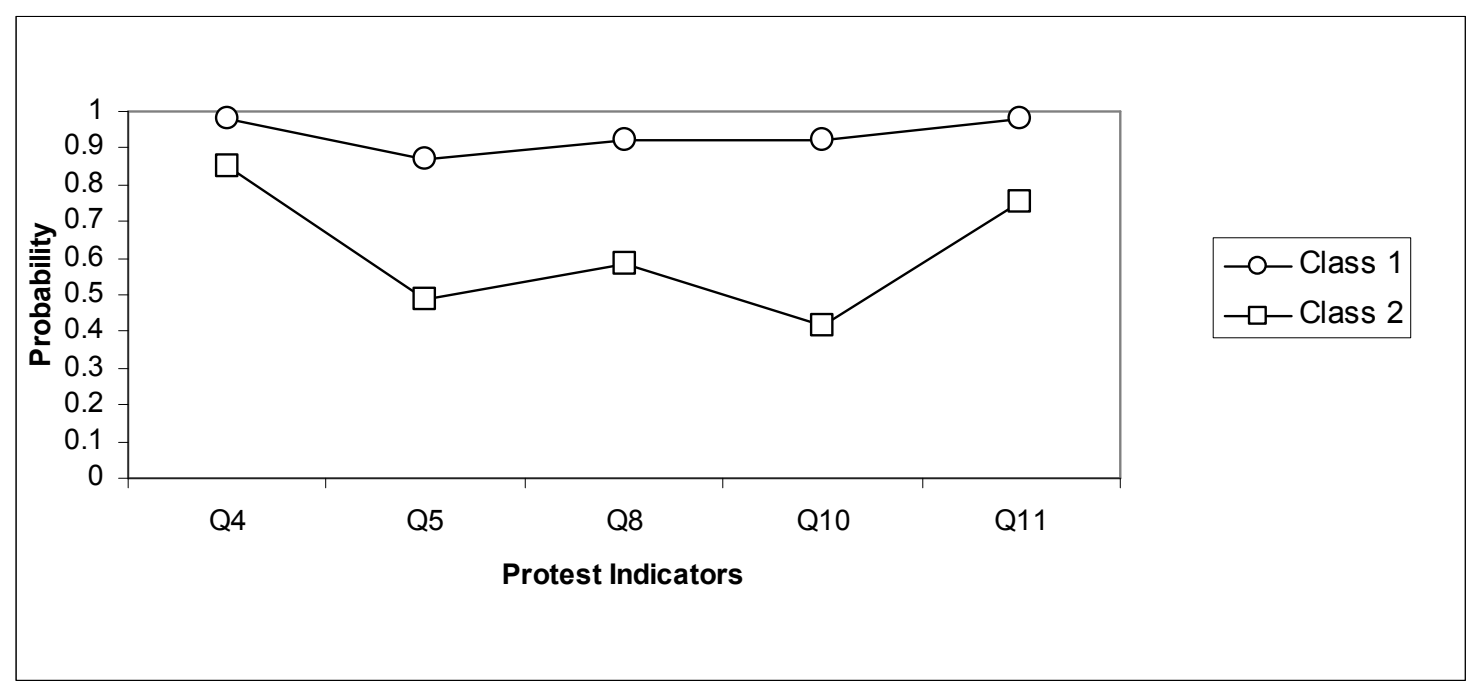

Figure 2. Probability of indicating levels 4-5 for the protest indicators in Model 1 (without justification bias)

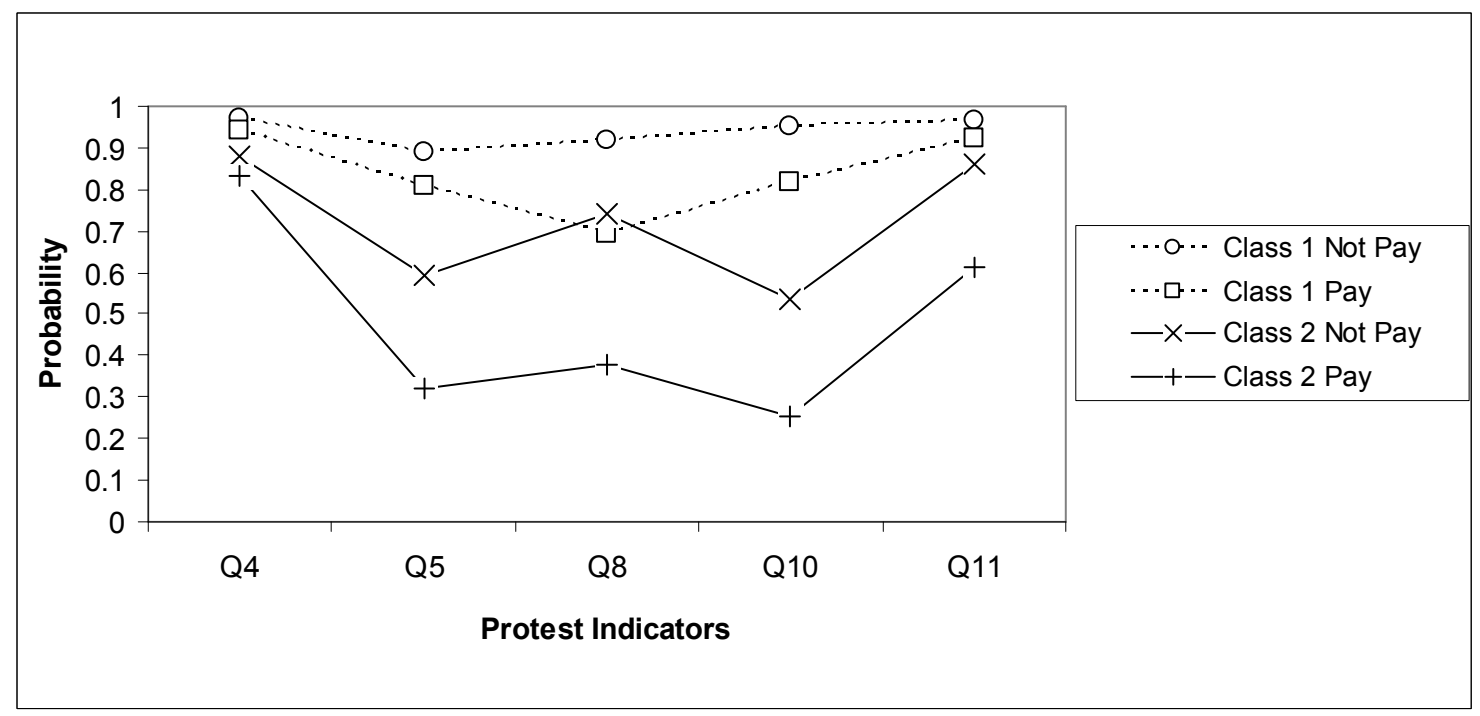

Figure 3. Probability of indicating levels 4-5 for the protest indicators in Model 1J (with justification bias) 